\title{
The effect of ultrasonic impact-frictional treatment on the surface roughness and hardening of 09Mn2Si constructional steel
}

\author{
N. V. Lezhnin ${ }^{\dagger, 1}$, A. V. Makarov ${ }^{1,2,3}$, S. N. Luchko ${ }^{1}$ \\ †nlezhnin@bk.ru \\ ${ }^{1}$ M. N. Miheev Institute of Metal Physics, UB RAS, 18 S. Kovalevskaya St., Ekaterinburg, 620108, Russia \\ ${ }^{2}$ Institute of Engineering Science, UB RAS, 34 Komsomolskaya St., Yekaterinburg, 620049, Russia \\ ${ }^{3}$ Ural Federal University n. a. the first President of Russia B. N. Yeltsin, 19 Mira St., Yekaterinburg, 620002, Russia
}

The paper compares the strengthening of constructional steel 09Mn2Si achieved by traditional ultrasonic impact treatment (UIT), and, the new method of ultrasonic impact-frictional treatment (UIFT), proposed by the authors. UIT is usually performed normally on the surface of the part with lubrication in the contact zone. The idea of UIFT is based on plastic shear deformation, activated by the friction effect of impulse impacts at a certain angle to the surface to be processed. In order to raise the friction coefficient, UIFT is performed without lubrication. It is shown that a decrease in the load application angle to the sample surface $(\alpha)$ increases the depth and hardness of the deformed surface layer of 09G2S structural steel. At the same time, the strengthening effect of treatment in the range of angles of $90-70^{\circ}$ mainly manifests itself in a thin (a few microns) near-surface layer, and the surface roughness remains almost unchanged. A further decrease in the angle increases the contribution of the friction component. Thus, UIFT at $\alpha=50^{\circ}$ gives the depth of the deformed layer 1.5 times, and the surface hardness is 2.5 times higher than after the traditional UIT. It was found that the profile of the pile-ups behind a moving instrument changed from symmetrical after UIT to shifted in the impact direction after UIFT, which led to a twofold increase in surface roughness for $\alpha=50^{\circ}$. It was established that reduction of the UIFT scanning step from $0.2 \mathrm{~mm}$ to $0.1 \mathrm{~mm}$ (load of $149 \mathrm{~N}$ and processing speed of $600 \mathrm{~mm} / \mathrm{min}$ ), improved the surface roughness $R_{a}$ by a factor of 5 from $3.9 \mu \mathrm{m}$ to $0.7 \mu \mathrm{m}$. A further decrease in the scanning step resulted in a surface coarsening due to fatigue degradation.

Keywords: ultrasonic impact treatment, surface plastic deformation, constructional steel, surface roughness.

УДК: 621.9.048.6

\section{Влияние ультразвуковой ударно-фрикционной обработки на упрочнение и топографию поверхности конструкционной стали 09Г2С}

\author{
Лежнин Н. В. ${ }^{\dagger, 1}$, Макаров А. В. ${ }^{1,2,3}$, Лучко С. Н. ${ }^{1}$ \\ ${ }^{1}$ Институт физики металлов им. М. Н. Михеева, УрО РАН, ул. С. Ковалевской, 18, Екатеринбург, 620108, Россия \\ ${ }^{2}$ Институт машиноведения, УрО РАН, ул. Комсомольская, 34, Екатеринбург, 620049, Россия \\ ${ }^{3}$ Уральский федеральный университет им. первого президента России Б. Н. Ельцина, ул. Мира, 19, \\ Екатеринбург, 620002, Россия
}

В работе проведено сравнение эффективности упрочнения конструкционной стали 09Г2С методами традиционной ультразвуковой ударной обработки (УЗУО) и предложенной авторами ультразвуковой ударно-фрикционной обработки (УЗУФО). УЗУО выполняется с приложением усилия по нормали к поверхности детали со смазкой в зоне контакта. Идея УЗУФО состоит в ударном воздействии под углом к обрабатываемой поверхности без смазки для активизации пластической деформации сдвигом в приповерхностном слое материала за счет усиления фрикционного воздействия. Показано, что с уменьшением угла приложения нагрузки к обрабатываемой поверхности и исключением смазки из зоны контакта, наблюдается рост твердости и глубины деформированного поверхностного слоя конструкционной стали 09Г2С. При этом в диапазоне углов обработки $90-70^{\circ}$ упрочняющий эффект от фрикционного воздействия в основном проявляется в тонком (несколько микрон) приповерхностном 
слое, а шероховатость поверхности практически не меняется. С дальнейшим уменьшением угла вклад фрикционного воздействия усиливается, так для УЗУФО под углом 50 к поверхности образца глубина деформированного слоя в 1.5 раза, а его твердость 2.5 раза выше, чем при традиционной УзУО. Обнаружено, что профиль валиков пластически вытесненного металла меняется с симметричного при УЗУО на смещенный в направлении удара при УЗУФО. Это приводит к двукратному росту параметра шероховатости поверхности $R_{a}$ при $\alpha=50^{\circ}$. Установлено, что при уменьшении шага сканирования от 0.2 до 0.1 мм при проведении УЗУФО с прижимной нагрузкой 149 Н и скоростью обработки 600 мм/мин происходит снижение параметра шероховатости $R_{a}$ в 5 раз: с 3.9 до 0.7 мкм. Дальнейшее уменьшение шага сканирования приводит к перенаклепу поверхностного слоя и огрублению поверхности.

Ключевые слова: ультразвуковая упрочняющая обработка, поверхностная пластическая деформации, конструкционная сталь, шероховатость поверхности.

\section{1. Введение}

Поверхность детали подвергается наиболее интенсивному воздействию в условиях эксплуатации, поэтому параметры поверхностного слоя оказывают существенное влияние на характеристики, определяющие работоспособность изделий, такие как износостойкость, усталостная долговечность и коррозионная стойкость. Перспективным направлением в улучшении свойств различных материалов является поверхностное пластическое деформирование. Существует ряд методов для создания на поверхности металла упрочненного слоя с измельченной структурой в результате интенсивного механического воздействия: фрикционная $[1,2]$ и дробеструйная обработки [3], ультразвуковая обработка шариками в вакууме [4] или инструментом, колеблющимся с ультразвуковой частотой $[5,6]$, обработка трением с перемешиванием [7] и другие. Преимуществом таких обработок является возможность изменять свойства поверхности при сохранении структуры изделия в целом и создавать благоприятные сжимающие напряжения в упрочненном слое с плавным переходом к основе [8].

Применяемая для поверхностного модифицирования различных материалов ультразвуковая ударная обработка (УЗУО) [5,9-11] обычно проводится в смазке твердосплавным индентором, колеблющемся с ультразвуковой частотой по нормали к обрабатываемой поверхности. Если в результате УЗУО неровности поверхности сглаживаются частично, ее можно отнести к отделочно-упрочняющей обработке; если формируется полностью новая поверхность, УЗУО идентифицируется как упрочняющая обработка [12]. Для эффективного упрочнения требуется применение бо́льших нагрузок и амплитуд колебаний инструмента или многократная обработка поверхности, что может приводить к огрублению поверхности [13].

В отличие от стандартной УЗУО, ультразвуковая ударно-фрикционная обработка (УЗУФО) [14,15] проводится по методу наклонного удара индентора под углом к обрабатываемой поверхности, меньшим $90^{\circ}$, в отсутствии смазки, что обеспечивает усиление фрикционного взаимодействия индентора с металлом и соответствующее увеличение сдвиговой составляющей пластической деформации. Идея ударно-фрикционной обработки заключается в совмещении значительных степеней пластической деформации металла за счет больших давлений при высокоэнергетическом ультразвуковом ударном воздействии и активизации ротационной моды пластического течения за счет сдвиговых деформаций при фрикционном воздействии. Это способствует реализации условий, близких к сдвигу под высоким давлением и, как следствие, измельчению зерна вплоть до субмикро- и наноуровней [15].

Целью настоящего исследования являлось изучение возможностей деформационного упрочнения и особенностей формирования топографии поверхности конструкционной стали 09Г2С при использовании нового способа ультразвуковой ударно-фрикционной обработки в сравнении с традиционной ультразвуковой ударной обработкой.

\section{2. Материалы и методика}

Исследовали сталь 09Г2С состава в масс.\%: 0.09\% С; $1.63 \% \mathrm{Mn} ; 0.60 \% \mathrm{Si}$, остальное - Fe. Образцы размером $40 \times 20 \times 10$ мм вырезали из листовой стали и подвергали нормализации от $950^{\circ} \mathrm{C}$, механическому шлифованию, полированию и ультразвуковой упрочняющей поверхностной обработке.

Обработку по схеме, представленной на Рис. 1, проводили с использованием установки ИЛ4-2 твердосплавным индентором (1) из сплава ВК8 с радиусом полусферы $R=3$ мм, закрепленного на волноводе (2) и магнитострикционном элементе (3), колеблющимся с частотой 22 кГц и амплитудой $f=20$ мкм. К инструменту прикладывали нагрузку $P=149 \mathrm{H}$. Перемещение образцов осуществляли с помощью двухкоординатного

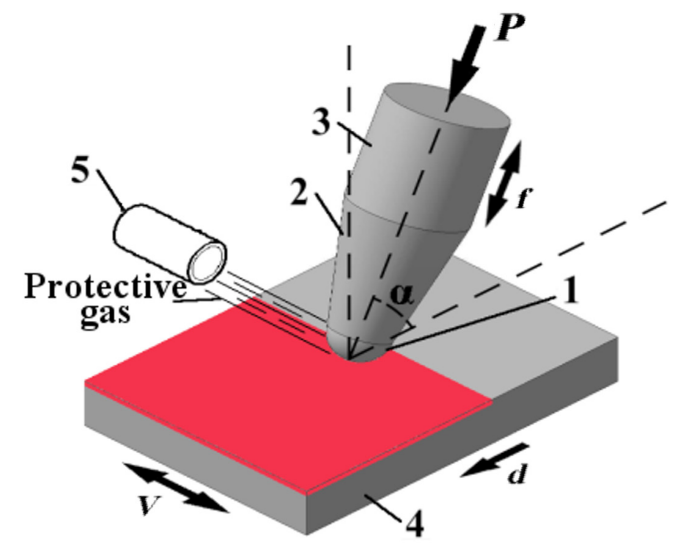

Рис. 1. Схема ультразвуковой ударно-фрикционной упрочняющей обработки.

Fig. 1. Ultrasonic impact-frictional treatment scheme. 
стола с ЧПУ со скоростью $V=600$ мм/мин и шагом сканирования $d=0.2,0.1$ и 0.06 мм. В случае УЗУО при обработке по нормали к поверхности для охлаждения и защиты обрабатываемой поверхности образца (4) применяли индустриальное масло И-40, а в случае УЗУФО через систему (5) осуществляли обдув аргоном. Аргон служил в качестве защитной атмосферы для предотвращения охрупчивания кислородом диффузионно-активного высокодисперсного поверхностного слоя, формируемого в ходе УЗУФО. При использовании среды аргона ультразвуковую обработку проводили как по нормали $\left(\alpha=90^{\circ}\right)$, так и под углами $\alpha=80-50^{\circ}$ (УЗУФО) к поверхности стали.

Для определения микротвердости поверхности и толщины упрочненного слоя на поперечных шлифах использовали твердомер SHIMADZU HMV-G21DT. Измерения проводили по методу восстановленного отпечатка при нагрузках на индентор Виккерса 98 мН $(10$ гс) и $980 \mathrm{mH}(100$ гс). На оптическом 3D-профилометре Wyko NT-1100 исследовали микрорельеф обработанной поверхности при увеличении 50 крат на участках площадью $0.9 \times 1.2$ мм и субмикрорельеф при увеличении 1000 крат на участках площадью $42.5 \times 55.8$ мкм.

\section{3. Результаты и их обсуждение}

На Рис. 2 представлены поперечные профили одиночных проходов инструмента при УзУО (Рис. 2 а) и УЗУФО под углом 50 (Рис. 2 b). Из Рис. 2 а следует, что при ударном воздействии перпендикулярно обрабатываемой поверхности по обеим сторонам дорожки формируются симметричные пластические валики из вытесняемого индентором металла. В соответствии со схемой на Рис. 1 угол наклона оси инструмента при ударно-фрикционной обработке изменяется в плоскости, перпендикулярной направлению скорости перемещения образца $V$. Такая ориентация ударного воздействия вызывает характерное смещение бокового валика в направлении удара и увеличение его размера (Рис. 2b) [16,17]. Этот волнистый рельеф, обусловленный проходами колеблющегося инструмента со скоростью $V$, определяет топографию обработанной поверхности.

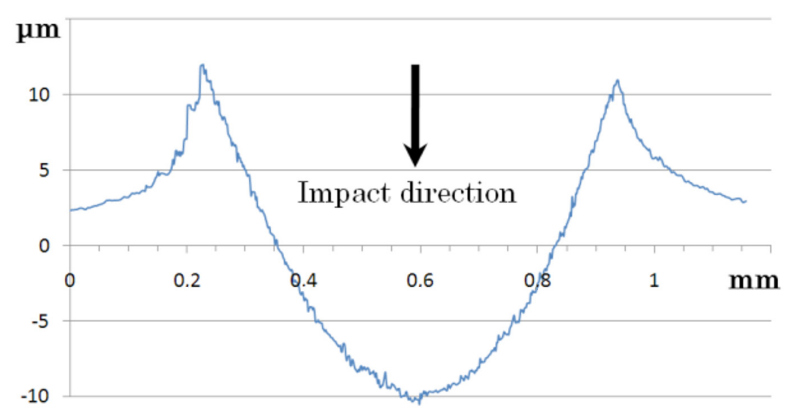

a
На Рис. 3 показано влияние угла а на поперечный микрорельеф и субмикрорельеф поверхности образов из стали 09Г2С после УЗУФО с шагом сканирования $d=0.2$ мм. Анализ кривой 1 на Рис. 3 показывает, что в диапазоне углов обработки $\alpha=90^{\circ}-70^{\circ}$ параметр шероховатости поперечного микрорельефа остается приблизительно на одном уровне $R_{a}=1.4-1.6$ мкм, затем при угле обработки $\alpha=60^{\circ}$ происходит его рост до $R_{a}=2.2$ мкм и при $\alpha=50^{\circ}-$ до $R_{a}=3.9$ мкм. Так как поперечный микрорельеф формируется в результате наложения соседних проходов (дорожек), эффект от искажения их профиля, показанный на Рис. 2, усиливается с уменьшением угла между инструментом и поверхностью при УЗУФО.

Выраженное влияние угла обработки на топографию поверхности указывает на необходимость учета данного параметра в дополнение к основным технологическим параметрам ультразвуковой ударной обработки, таким как прижимное усилие, амплитуда колебаний, скорость перемещения образца, шаг сканирования (поперечная подача образца) и геометрия индентора.

Анализ субмикрорельефа (Рис. 3, кривая 2) показывает, что при небольшом отклонении инструмента

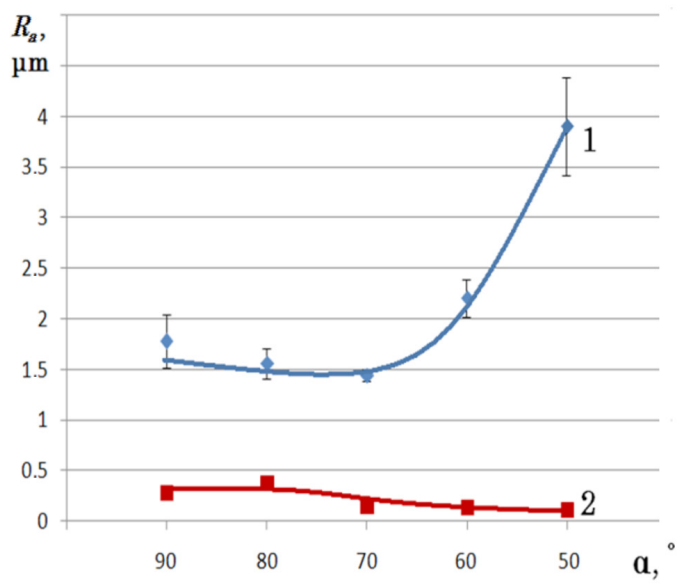

Рис. 3. Влияние угла а при УЗУФО на параметр шероховатости поверхности $R_{a}$ стали 09Г2С: поперечный микрорельеф (1) и субмикрорельеф (2).

Fig. 3. Surface roughness $R_{a}$ of $09 \mathrm{Mn} 2 \mathrm{Si}$ steel depending on UIFT angle $\alpha$ : transverse microrelief (1), submicrorelief (2).

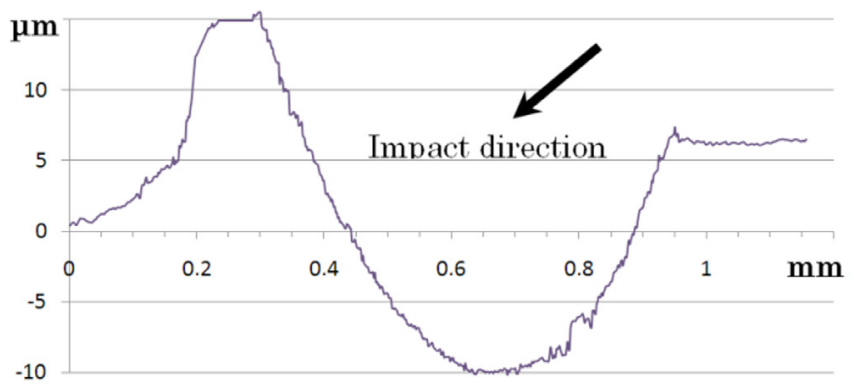
$b$

Рис. 2. Поперечный профиль участка поверхности стали 09Г2С после одиночного прохода при УЗУО под углом $\alpha=90^{\circ}$ (a) и УЗУФО под углом $\alpha=50^{\circ}(\mathrm{b})$.

Fig. 2. Transverse surface profile of 09Mn2Si steel after single pass of UIT (a) and UIFT at $\alpha=50^{\circ}$ (b). 
от нормали к поверхности параметр $R_{a}$ изменяется незначительно и для углов $\alpha=90^{\circ}-80^{\circ}$ находится на уровне $R_{a}=0.23-0.29$ мкм. Уменьшение угла обработки до $\alpha=60^{\circ}-50^{\circ}$ приводит к снижению среднего арифметического отклонения профиля шероховатости поверхности до $R_{a}=0.15-0.09$ мкм. Это может быть обусловлено эффектом локального выглаживания поверхности из-за усиления фрикционного воздействия инструмента при меньшем угле обработки. Наблюдаемые низкие значения параметра шероховатости субмикрорельефа свидетельствуют о том, что в процессе УЗУФО без смазки на поверхности стали 09Г2С не получают развития процессы адгезионного схватывания и усталостного разрушения, приводящие к ухудшению поверхности. Установленные для субмикрорельефа значения параметра шероховатости $R_{a}=0.15-0.09$ мкм являются, по-видимому, предельно достижимыми при проведении УЗУФО.

Одним из ключевых технологических параметров обработки, определяющих возникновение на поверхности параллельных валиков и впадин металла, является шаг сканирования (наряду с нагрузкой на инструмент, амплитудой его колебаний, пластичностью обрабатываемого материала). Рис. 4 демонстрирует зависимость шероховатости поверхности образцов от шага сканирования при проведении УЗУФО под углом $a=50^{\circ}$. Видно, что уменьшение шага сканирования $d$ от 0.2 до 0.1 мм приводит к уменьшению параметра шероховатости поверхности в 5 раз (до $R_{a}=0.7$ мкм), что соответствует шероховатости поверхности после чистовой шлифовки. При дальнейшем уменьшении шага сканирования до 0.06 мм улучшения чистоты обработки поверхности не происходит. Напротив, наблюдается рост параметра шероховатости вследствие перенаклепа поверхности и возникновения очагов контактного усталостного разрушения.

На Рис. 5 представлены результаты измерения микротвердости образцов после ультразвуковой ударной обработки под различными углами к поверхности

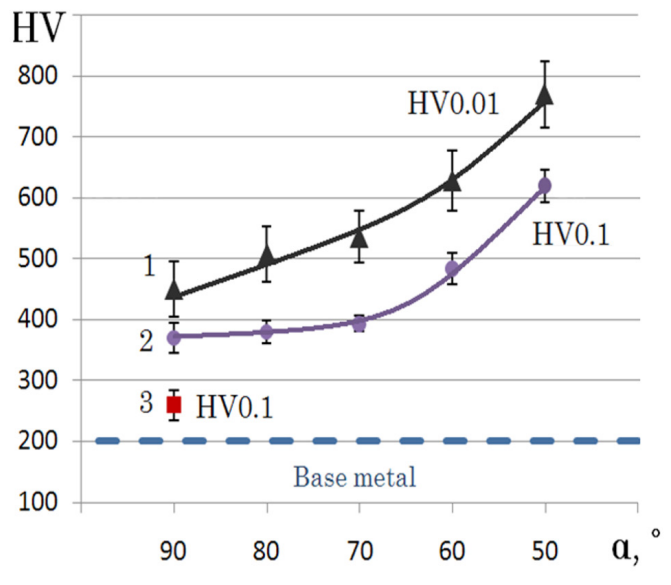

a

Рис. 5. Влияние угла между инструментом и обрабатываемой поверхностью а и среды ультразвуковой обработки на микротвердость поверхности (а) и изменение микротвердости HV0.01 в зависимости от расстояния от поверхности $h$ образцов стали 09Г2С после УЗУФО при $\alpha=50^{\circ}$ и УЗУО (b): $1,2-$ УЗУФО в среде аргона; $3-$ УЗУО в смазке при $\alpha=90^{\circ}$.

Fig. 5. The surface microhardness of $09 \mathrm{Mn} 2 \mathrm{Si}$ steel vs the angle between the instrument and the sample surface $\alpha$ and medium of the ultrasonic treatment (a) and the microhardness HV0.01 depending on the distance from the surface $h$ for samples after UIFT at $\alpha=50^{\circ}$ and UIT (b): 1, 2- UIFT in argon; $3-$ UIT at $\alpha=90^{\circ}$ in lubrication.

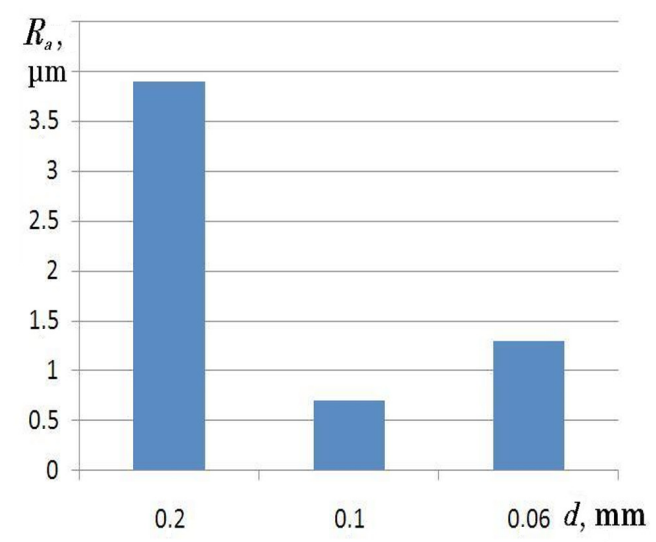

Рис. 4. Влияние шага сканирования $d$ при УЗУФО под углом $\alpha=50^{\circ}$ на параметр шероховатости поверхности $R_{a}$ стали 09Г2С.

Fig. 4. Surface roughness $R_{a}$ vs feed rate $d$ relationship for UIFT $\alpha=50^{\circ}$.

образца. Нагрузки 98 мН (Рис. 5 а, кривая 1) и 980 мН (Рис. $5 \mathrm{a}$, кривая 2) при измерении микротвердости позволяют оценить деформационное упрочнение в приповерхностном слое различной толщины. Глубина внедрения индентора в данном случае составляет порядка 1 и 3 мкм, соответственно.

Микротвердость образцов из стали 09Г2С в нормализованном состоянии составляет 200 HV0.1 (Рис. $5 \mathrm{a}$, пунктир). После проведения стандартной УЗУО (при воздействии по нормали к поверхности) с использованием смазки микротвердость поверхности стали возрастает до $260 \mathrm{HV} 0.1$ (Рис. 5a, точка 3), что на $30 \%$ больше микротвердости исходного материала. Исключение смазки из зоны контакта позволяет повысить микротвердость на $85 \%$ от исходной и достичь микротвердости поверхности в $370 \mathrm{HV} 0.1$ (Рис. 5a, кривая 2). Это свидетельствует о росте коэффициента (силы) трения и, как следствие, увеличении накопленной деформации в поверхностном слое. При уменьшении угла а наблюдается рост микротвердости поверхности.

HV0.01

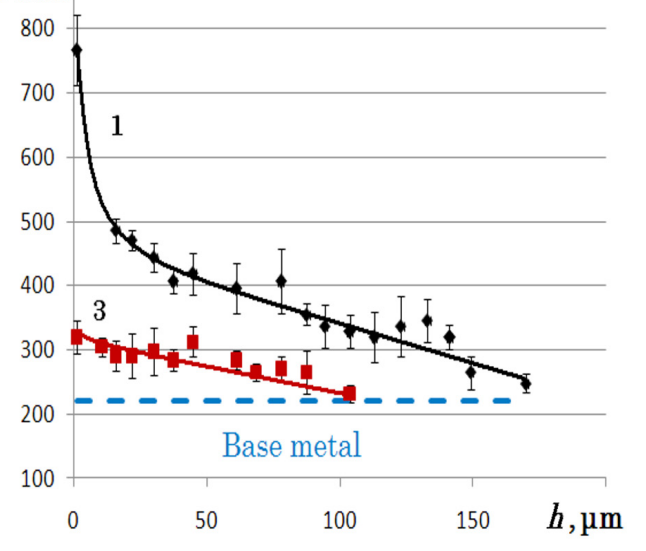


Причем при нагрузке на индентор 98 мН наблюдается монотонный рост значений микротвердости до 760 HV0.01 при угле $\alpha=50^{\circ}$ (Рис. 5 а, кривая HV0.01), в то время как в случае измерений с нагрузкой $980 \mathrm{mH}$ заметный рост значений микротвердости регистрируется лишь при углах обработки $\alpha=60^{\circ}-50^{\circ}$ и достигает $620 \mathrm{HV} 0.1$ при $\alpha=50^{\circ}$ (Рис. 5 а, кривая HV0.1). Такой характер изменения микротвердости при разных нагрузках на индентор микротвердомера свидетельствует о локализации интенсивного упрочнения лишь в тонком приповерхностном слое при проведении УЗУФО с относительно небольшим отклонением оси инструмента от нормали. В работе [15] в результате УЗУФО в аргоне при угле $\alpha=80^{\circ}$ отмечали увеличение микротвердости поверхности стали 09Г2С до 415 HV0.025, что существенно ниже упрочнения рассматриваемой стали при углах обработки $\alpha=60-50^{\circ}$ (см. Рис. 5 a).

Из Рис. 5b следует, что УЗУФО $\left(a=50^{\circ}\right)$ приводит не только к повышенному упрочнению поверхности (до 760 HV0.01), но и к увеличению толщины деформационно-упрочненного слоя по сравнению с УЗУО. Так для традиционной УЗУО со смазкой при $\alpha=90^{\circ}$ упрочнение наблюдается в слое толщиной порядка 100 мкм при максимальной микротвердости на поверхности 320 HV0.01 (Рис. 5b, кривая 3), в то время как при УЗУФО под углом $\alpha=50^{\circ}$ в аргоне упрочненный слой достигает толщины более 150 мкм (Рис. 5b, кривая 1).

Значительный вклад фрикционного воздействия в упрочнение при УЗУФО проявляется в росте микротвердости поверхности более чем в 3 раза по сравнению с твердостью недеформированной стали и более чем в 2 раза по сравнению с микротвердостью после УзУО в смазке. Повышенное упрочнение стали 09Г2С с исходной феррито-перлитной структурой в результате УЗУФО можно объяснить в первую очередь более эффективным измельчением зерен феррита вплоть до субмикро- и нанокристаллического состояний [15] и ростом плотности дислокаций, т.е. активизацией зернограничного и дислокационного механизмов упрочнения.

Отклонение оси инструмента от нормали к поверхности вносит сдвиговую составляющую пластической деформации в плоскости обрабатываемой поверхности за счет трения скольжения между образцом и инструментом в результате появления тангенциальных составляющих прижимного усилия и перемещения индентора, а исключение смазочных материалов приводит к увеличению коэффициента трения в паре «обрабатываемый материал-индентор». Трение способствует развитию ротационной моды пластической деформации, которая способствует увеличению доли большеугловых разориентировок и измельчению зеренной структуры [1]. При проведении УзУО под прямым углом к поверхности, подобные условия деформирования возникают лишь в ограниченных микрообъемах материала, которые вытесняются из-под индентора в процессе его вдавливания.
Интенсивная пластическая деформация при высокоэнергетическом ультразвуковом ударном воздействии вызывает также фрагментацию и частичное деформационное растворение (диссоциацию) цементитных пластин перлитных колоний в приповерхностном слое стали с исходной феррито-перлитной структурой $[15,18]$. Высокая цикличность деформационного нагружения при ультразвуковых обработках способствует развитию указанных процессов, которые протекают в структуре пластинчатого перлита даже в условиях многоциклового усталостного нагружения при напряжениях, меньших предела текучести материала [19]. Деградация цементита перлитных колоний в низкоуглеродистой конструкционной стали активно развивается также под действием фрикционной обработки скользящим твердосплавным индентором [20]. При переходе углерода из цементита в твердый раствор он не только повышает прочность стали за счет твердорастворного упрочнения, но и эффективно закрепляет дислокации, тем самым упрочняя и стабилизируя структуру деформированного слоя [2,9]. Таким образом, важный вклад в наблюдаемое повышенное упрочнение феррито-перлитной стали 09Г2С при УЗУФО вносит более интенсивное диспергирование и растворение цементита в перлитных колониях, обусловленное усилением сдвиговой деформации в условиях нагружения наклонным ударом и без применения смазки, уменьшающей фрикционное воздействие деформирующего инструмента.

\section{4. Заключение}

Рассмотрен новый метод ультразвуковой ударнофрикционной обработки (УЗУФО), проводимой по методу наклонного удара в защитной среде аргона. Показаны преимущества УЗУФО при упрочнении конструкционной стали 09Г2С с исходной ферритоперлитной структурой по сравнению с традиционной ультразвуковой ударной обработкой (УЗУО), выполняемой при ударном воздействии по нормали к поверхности с использованием смазки.

Установлено, что при УЗУФО по мере уменьшения угла между деформирующим инструментом и обрабатываемой поверхностью а упрочнение стали возрастает, достигая при $\alpha=50^{\circ}$ значений микротвердости $620 \mathrm{HV} 0.1$ и $760 \mathrm{HV} 0.01$, что существенно выше, чем при УЗУО (260 HV0.1 и 320 HV0.01).

Показано, что толщина упрочненного слоя увеличивается с 100 мкм при УЗУО до 150 мкм при УЗУФО $\left(\alpha=50^{\circ}\right)$.

Методом УЗУФО получены поверхности с параметрами шероховатости микрорельефа $R_{a}=0.7$ мкм и субмикрорельефа $R_{a}=0.15-0.09$ мкм. Таким образом, при должном сочетании технологических параметров УЗУФО, открываются перспективы достижения низкого уровня шероховатости поверхности стали (в пределе соответствующего субмикрорельефу).

Полученные результаты позволяют рассматривать ультразвуковую ударно-фрикционную обработку в качестве перспективного финишного способа поверхностного упрочнения конструкционной низкоугеродистой стали с феррито-перлитной структурой. 
Благодарность/Acknowledgment. Авторы выражают благодарность Гибзуну М.С., Соболевой Н.Н. и Скорьниной П.А. за помощь в проведении профилометрических исследований. Работа выполнена в рамках государственного задания МИНОБРНАУКИ России по темам № АAAA-A18-118020190116-6 (проект № 18-10-2-39) u № АААА-А18-118020790148-1 при поддержке РФФИ (проект № 18-38-00868_мол_а). Измерения микротвердости и 3D-профилометрия выполнены в ЦКП «Пластометрия» ИМАШ УрО РАН./The research was carried out within the state assignment of Minobrnauki of Russia on themes No. AAAA-A18-118020190116-6 (project No. 18-10-2-39) and № AAAA-A18-118020790148-1, supported by RFBR (project No. 18-38-00868). Microhardness and 3D-profilometry tests were performed in the "Plastometriya" collective use center of the Institute of Engineering Science UB RAS.

\section{Литература/References}

1. A. V. Makarov, L.G. Korshunov. The Physics of Metals and Metallography. 120 (3), Inprint (2019). Crossref

2. R.A. Savrai, A.V. Makarov, I. Yu. Malygina, E.G. Volkova. Materials Science and Engineering: A. 734, 506 (2018). Crossref

3. H. Kovacı, Y. B. Bozkurt, A. F. Yetim, M. Aslan, A. Çelik. Surface and Coatings Technology. 360, 78 (2019). Crossref

4. B. Arifvianto, Suyitno, M. Mahardika. Applied Surface Science. 258 (10), 4538 (2012). Crossref

5. V.P. Alekhin, O.V. Alekhin. Mashinostroenie i inzhenernoe obrazovanie. 4 (13), 2 (2007). (in Russian) [В.П. Алехин, О.В. Алехин. Машиностроение и инженерное образование. 4 (13), 2 (2007).]

6. X. Yang, X. Wang, X. Ling, D. Wang. Results in Physics. 7, 1412 (2017). Crossref

7. T.R. McNelley. Letters on materials. 5 (3), 246 (2015). Crossref

8. G. Q. Wang, M. K. Lei, D. M. Guo. Procedia CIRP. 45, 323 (2016). Crossref
9. A. V.Panin.Ul'trazvukovayaobrabotkakonstruktsionnykh materialov. Tomsk, Publishing House of Tomsk State University (2016) 172 p. (in Russian) [A. В. Панин. Ультразвуковая обработка конструкционных материалов. Томск, Издательский Дом Томского государственного университета (2016) 172 с.]

10. H. Zhang, R. Chiang, H. Qin, Zh. Ren, X. Hou, D. Lin, G. L. Doll, V. K. Vasudevan, Y. Dong, C. Ye. International Journal of Fatigue. 103, 136 (2017). Crossref

11. S. P.Chenakin, V. S. Filatova, I. N. Makeeva, M. A. Vasylyev. Applied Surface Science. 408, 11 (2017). Crossref

12. Z. G. Kovalevskaya, P. V. Uvarkin, A. I. Tolmachev. Russ J Nondestruct Test. 48 (3), 10 (2012). Crossref

13. A.V. Panin, M.S. Kazachenok, A.I. Kozelskaya, R.R. Hairullin, E.A. Sinyakova. Materials Science and Engineering: A. 647, 43 (2015). Crossref

14. Patent RF №2643289, 2018. (in Russian) [Патент РФ № 2643289, 2018.]

15. A. V. Makarov, R. A. Savrai, I. Yu. Malygina, E. G. Volkova, S. V. Burov. AIP Conference Proceedings. 2053, 020006 (2018). Crossref

16. B. N. Mordyuk, G.I. Prokopenko. Journal of Sound and Vibrations. 308 (3-5), 855 (2007). Crossref

17. J. O. Peters, B.L. Boyce, X. Chen, J. M. McNaney, J.W. Hutchinson, R.O. Ritchie. Engineering Fracture Mechanics. 69, 1425 (2002). Crossref

18. Z.G. Kovalevskaya, Y.F. Ivanov, O.B. Perevalova, V.A. Klimenov, P.V. Uvarkin. The Physics of Metals and Metallography. 114 (1), 41 (2013). Crossref

19. A.V. Makarov, R.A. Savrai, V.M. Schastlivtsev, T.I. Tabatchikova, I.L. Yakovleva, L. Yu. Egorova. Physics of Metals and Metallography. 111 (1), 95 (2011). Crossref

20. A.V. Makarov, R.A. Savrai, N.A. Pozdejeva, S.V. Smirnov, D.I. Vichuzhanin, L.G. Korshunov, I.Yu. Malygina. Surface and Coatings Technology. 205 (3), 841 (2010). $\underline{\text { Crossref }}$ 